\title{
Determinants of epoxy allergy in the construction industry: a case-control study
}

\author{
Ton Spee ${ }^{1,2}$, Johan G. Timmerman ${ }^{1}$, Reinhold Rühl' ${ }^{3}$, Klaus Kersting ${ }^{3}$, Dick J. J. Heederik ${ }^{1}$ \\ and Lidwien A. M. Smit ${ }^{1}$
}

${ }^{1}$ Division Environmental Epidemiology, Institute for Risk Assessment Sciences, Utrecht University, P.O. Box 80178, NL-3508TD Utrecht, The Netherlands, ${ }^{2}$ Arbouw, P.O. Box 213, NL-3840AE Harderwijk, The Netherlands, and ${ }^{3}$ Berufsgenossenschaft für die Bauwirtschaft, Hungener Straße 6 D-60389, Frankfurt, Germany

doi:10.1111/cod.12529

\section{Summary}

Background. Workers exposed to epoxy products are at risk of developing allergic contact dermatitis.

Objectives. To compare workers throughout the German construction industry with and without skin allergy to epoxy resins, hardeners, and/or reactive diluents, and to investigate which determinants are related to the development of epoxy allergy.

Methods. A questionnaire was completed by 179 epoxy allergy cases, and 151 epoxy workers as controls. Crude and adjusted odds ratios (ORs) and 95\% confidence intervals (CIs) were estimated by the use of backwards stepwise logistic regression analysis. A multiple imputation approach was used to deal with missing data.

Results. Epoxy allergy was associated with an unusually high level of exposure to epoxy products [OR $2.13(95 \% \mathrm{CI}$ : 1.01-4.51)], wearing short sleeves or short trousers [OR 2.38 (95\%CI: 1.03-5.52)], and not always using the correct type of gloves [OR 2.12 (95\%CI: 1.12-4.01)]. A monotonic increasing risk was found with increasing exposure hours per week [OR 1.72 (95\%CI: 1.39-2.14)]. Not using skin cream was inversely associated with epoxy allergy [OR 0.22 (95\%CI: 0.08-0.59)]. Years working with epoxy products were inversely associated with epoxy allergy [OR 0.41 (95\%CI: $0.27-0.61)$ per 10-year increase], suggesting a healthy worker survivor effect.

Conclusions. Occupational epoxy allergy may be prevented by improving occupational hygiene behaviour and personal protection.

Key words: epidemiology; occupational; occupational hygiene behaviour; prevention.

Because of their unique technical properties, epoxy products are widely used in the construction industry. Effective substitutes are hardly available, and the number of applications is still growing (1). Unfortunately, epoxies are strong sensitizers. Although chromate is still the most

Correspondence: Lidwien A.M. Smit, Institute for Risk Assessment Sciences, Division Environmental Epidemiology, PO Box 80178, 3508 TD Utrecht, The Netherlands. Tel: +31 30 2538696; Fax: +31 30 2539499. E-mail: l.a.smit@uu.nl

Conflicts of interest: None of the authors has a potential conflict of interest.

Accepted for publication 28 November 2015 common cause of allergy in the German construction industry, $>10 \%$ of all occupational allergies among construction workers are attributable to epoxy resin systems (2). In The Netherlands, it is estimated that approximately one of every five epoxy-exposed workers develops symptomatic dermal sensitization, which is often serious enough to lead to a change of job (3). Rømyhr et al. reported an incidence rate of 4.5/1000 person years, which corresponds to nearly one of five industrial painters who regularly work with epoxy resin systems, over a 40-year career (4).

The economic impact on society of epoxy allergies is high. Rühl and Wriedt estimated the cost of 
occupational epoxy allergies for the whole EU in 2003 to be $€ 40$ million (5). Financial compensation for work disability alone accounted for $>€ 1.4$ million in Germany in 2007. Furthermore, there are costs for medical treatment, absenteeism, employee replacement and retraining.

A few previous studies in epoxy workers suggested that poor occupational hygiene behaviour may increase the risk of skin exposure (6) and the development of epoxy allergy $(1,7)$. These studies evaluated working practices in 21 workers (6), and epoxy sensitization in 8 workers (1) and 22 workers (7), respectively. To the best of our knowledge, there are no adequately powered epidemiological studies that have systematically evaluated determinants of epoxy allergy among a larger group of workers from different companies representative of the industrial sector.

The aim of this case-control study was to investigate which determinants are related to the development of contact allergy against epoxy resins, hardeners, and/or reactive diluents. The policy information generated could form the basis for intervention strategies. The study focused on working practices, occupational hygiene behaviour, and personal protection.

\section{Materials and Methods}

\section{Study design and population}

A case-control study was conducted among epoxy workers with a recognized epoxy skin allergy and epoxy workers without such an allergy. Cases were ascertained from the files of the German statutory accident insurance of the construction sector [Berufsgenossenschaft der Bauwirtschaft (BGBAU)]. Epoxy allergy is confirmed in approximately 100-150 persons annually by BGBAU, so we decided to collect data over a retrospective 4-year period to include an adequate number of cases. Workers with an epoxy allergy recognized as an occupational disease between 1 January 2004 and 31 December 2007 were invited to participate in the study. For recognition as an occupational disease, epoxy allergy has to be confirmed by means of a patch test. Controls were recruited at companies that regularly work with epoxy products and, in part, at instruction sessions for working with epoxies.

Cases received a questionnaire at their home address. Controls received a questionnaire at the end of the instruction session or by mail. They were asked to complete the questionnaire at home. Postage-free return envelopes were supplied to both groups. Questionnaires were distributed between 2011 and 2012 (cases) and between 2011 and 2013 (controls).
Subjects who did not complete the questionnaire, or stated that they had not worked with epoxy products, were excluded from analysis. In the case group, subjects who stated that they were not allergic to epoxies were also excluded from data analysis. In the control group, subjects who stated that they were allergic to epoxy products, seldom or never worked with epoxy products, or only recently started working for the current employer, were excluded from data analysis.

\section{Questionnaire}

Data on epoxy exposure and potential confounders were collected by means of a self-administered questionnaire. The questionnaire included items on personal characteristics, atopic predisposition, respiratory symptoms, skin symptoms (for cases: skin symptoms at the time of diagnosis), products used, tasks performed and working practices, personal protection and hygiene, and education and training. Questions about respiratory (8) and skin (9) symptoms were adopted from existing, validated questionnaires. The questions about epoxy products, tasks, working practices, personal protection and hygiene, and education and training were developed by two persons (T.S. and K.K.) who are familiar with working with epoxy products in the construction industry. The questions about glove use were validated in a separate study (10).

To score subjects for hand dermatitis, we used a questionnaire based on Smit et al. (9) and Jungbauer et al. (11) with a score for each question, as shown in Table 1. A positive answer to all questions yields 9 points. A score of at least 3 points is classified as 'possible hand dermatitis', and a score of at least 5 points as 'hand dermatitis'.

Table 1. Symptom score used to define dermatitis and possible dermatitis

\begin{tabular}{|c|c|}
\hline Question & Points \\
\hline \multicolumn{2}{|l|}{$\begin{array}{l}\text { Have you had one of the following symptoms on your } \\
\text { hands or fingers in the past } 12 \text { months: }\end{array}$} \\
\hline - Red and swollen hands or fingers & 1 \\
\hline - Red hands or fingers with fissures & 2 \\
\hline - Vesicles on the hands or between the fingers & 2 \\
\hline - Raw or scaly hands with fissures & 1 \\
\hline - Itchy hands or fingers with fissures & 1 \\
\hline $\begin{array}{l}\text { Did one or more of these symptoms last for more than three } \\
\text { weeks? }\end{array}$ & 1 \\
\hline $\begin{array}{l}\text { Did one or more of these symptoms occur more than once } \\
\text { in the past } 12 \text { months? }\end{array}$ & 1 \\
\hline \multicolumn{2}{|c|}{$\begin{array}{l}\text { The last two questions were not asked in the case group, because, } \\
\text { among people suffering from epoxy allergy, the answers would be } \\
\text { positive by definition. Therefore, cases always score at least } 2 \text { points. } \\
\text { aA score of at least } 3 \text { points is classified as 'possible dermatitis', and a } \\
\text { score of at least } 5 \text { points as 'dermatitis'. }\end{array}$} \\
\hline
\end{tabular}


We used an additional questionnaire that showed pictures of dermatitis of increasing severity on the hands, but also on other parts of the body [see (12) for an example of the pictures]. This photo-questionnaire, developed by the Dutch Centre for Occupational Skin Diseases, which is reported to have a negative predictive value of $99 \%$ (13), was used for comparison with the symptom-based questionnaire and to estimate the severity of the symptoms.

\section{Statistical analyses}

Statistical analyses were carried out with SAS $^{\mathrm{TM}}$ version 9.4 (SAS System for Windows $^{\mathrm{TM}}$, SAS Institute, Cary, NC, USA) and R STUDIO for Windows ${ }^{\mathrm{TM}}$ (version 3.0.2).

To assess the association between epoxy allergy and various possible risk factors, crude and adjusted odds ratios (ORs) and 95\% confidence intervals (CIs) were estimated by the use of backwards stepwise logistic regression analysis. All determinants with univariate $p$-values of $<0.2$ were included in the initial model. At each step, the determinant with the highest $p$-value was removed from the model. The final model consisted of all variables that remained significant $(p<0.05)$. Determinants were corrected for all determinants in the final model to calculate adjusted ORs. A number of categorical questionnaire items were dichotomized for use in the regression analysis. Associations with continuous variables (years of working experience and hours per week working with epoxy products) were also analysed with a generalized additive model to evaluate the shape of the relationship.

As a sensitivity analysis, the analyses were repeated in a population in which controls with self-reported skin symptoms (but not necessarily epoxy allergy) were excluded. Analyses were also performed for only those cases who reported severe symptoms.

To deal with missing data, we used a multiple imputation approach. By assuming that missing data are missing at random, this method results in more precise estimates than those obtained in complete case analysis. A fully conditional specification method [described in (14)] was used to impute missing values. In total, 25 complete datasets were generated, analysed and combined by use of the MI and MIANALYZE procedures in SAS ${ }^{\mathrm{TM}}$. Imputations were based on case status and all variables shown in Table 3. Average attributable fractions were calculated according to Eide and Gefeller (15), with the SAS ${ }^{\mathrm{TM}}$ macro provided by Rückinger et al. (16).

\section{Ethical issues}

The project was carried out in accordance with the code of conduct 'Use of data in health research' from the Dutch
Federation of Biomedical Scientific Societies, which is in accordance with EU regulations (17). The purpose of the study was explained in a cover letter. Participation in the study was entirely voluntary, as was filling in the telephone number for retrieval of additional information. This was stated on the questionnaire. All participants signed an informed consent form.

\section{Results}

\section{Response to the questionnaire}

All 527 cases of epoxy allergy registered in the period under study received a questionnaire, 159 of which were returned as undeliverable. Of the remaining 368 cases, $185(50 \%)$ returned the questionnaire.

Among the control group, 828 questionnaires were disseminated, and 242 of the controls returned the questionnaire $(29 \%)$. Instruction sessions yielded 85 respondents; the remaining 157 were recruited directly at companies. Owing to logistic limitations, data collection from controls ran from 2009 until 2012. A total of 81 respondents were recruited at two large companies. The working practices at these companies were clearly different from those at other companies using epoxy products. To avoid spurious results owing to selection of controls from non-representative companies, it was decided to exclude workers from the large companies from data analysis.

Six respondents $(3 \%)$ from the case group and 10 respondents $(7 \%)$ from the control group were excluded from data analysis, for the reasons mentioned in Materials and Methods. Consequently, 179 cases and 151 controls were included in the analyses.

\section{Characteristics and activities of the respondents}

The characteristics of the study population are summarized in Table 2. Respondents could specify 16 different activities that applied to their tasks, and more than one answer was allowed. 'Corrosion protection' was most frequently mentioned $(56.4 \%, \mathrm{n}=186)$, followed by concrete repair by injection $(48.8 \%, \mathrm{n}=161)$ and industrial floor laying $(43.0 \%, \mathrm{n}=142)$. On average, controls had slightly more different tasks per person than cases (controls, 4.2 tasks per person; cases, 3.4 tasks per person).

According to the symptom-based questionnaire, 159 $(88.8 \%)$ cases possibly had hand dermatitis, with 100 of them having hand dermatitis. A total of 2 controls met the criteria for hand dermatitis, and 12 more for possible hand dermatitis (14 in total, 9.3\%).

According to the photo-questionnaire, 150 cases reported eczematous skin conditions $(83.8 \%)$ and 124 reported severe skin conditions (69.3\%). Among the 
Table 2. Characteristics of the study population of epoxy allergy cases and controls. q1, first quartile; q3, third quartile.

\begin{tabular}{|c|c|c|c|c|c|c|}
\hline \multirow[b]{2}{*}{ Variable } & \multicolumn{2}{|c|}{ Cases $(n=179)$} & \multicolumn{4}{|c|}{ Controls $(n=151)$} \\
\hline & Median & $q_{1}-q^{3}$ & Median & & $q 1-q 3$ & \\
\hline Age (years) & $41.5^{\mathrm{a}}$ & $32.0-49.0$ & $41.0^{\mathrm{b}}$ & & $29.0-49.0$ & \\
\hline Years of working with epoxy products & $6.0^{\mathrm{b}}$ & $3.0-12.0$ & $12.0^{\mathrm{b}}$ & & $7.0-20.0$ & \\
\hline Hours per week working with epoxy products & 25 & $9.0-40.0$ & 5 & & $2.0-15.0$ & \\
\hline Amount of product used per week $(\mathrm{lor} \mathrm{kg})^{\mathrm{d}}$ & 30 & $10.0-50.0$ & 20 & & $4.0-150.0$ & \\
\hline $\begin{array}{l}\text { Number of years between starting to work with epoxy products } \\
\text { and epoxy allergy diagnosis }(n=74)\end{array}$ & 3 & $2.0-8.0$ & - & & - & \\
\hline $\begin{array}{l}\text { Number of years between epoxy allergy diagnosis and filling in the } \\
\text { questionnaire }(n=137)\end{array}$ & 5 & $3.0-8.0$ & - & & - & \\
\hline \multirow{2}{*}{$\begin{array}{l}\text { Number of years between ceasing to work with epoxy products and } \\
\text { filling in the questionnaire }(n=87)\end{array}$} & 4 & $2.0-7.0$ & - & & - & \\
\hline & $n$ & $\%^{c}$ & & $\mathrm{n}$ & & $\%^{c}$ \\
\hline Possible dermatitis according to symptom-based questionnaire ${ }^{e}$ & 159 & 88.8 & & 12 & & 8.0 \\
\hline Dermatitis according to symptom-based questionnaire ${ }^{e}$ & 100 & 55.9 & & 2 & & 1.3 \\
\hline Symptoms according to photo-questionnaire & 150 & 83.8 & & 23 & & 15.2 \\
\hline Mild symptoms & 26 & 14.5 & & 9 & & 6.0 \\
\hline Severe symptoms & 124 & 69.3 & & 14 & & 9.3 \\
\hline
\end{tabular}

${ }^{a}$ At the time of epoxy allergy diagnosis.

${ }^{b}$ At the time of completing the questionnaire.

${ }^{\text {c}}$ Percentages of the total numbers of cases/controls.

${ }^{\mathrm{d} S o m e ~ s u p p l i e r s ~ s p e c i f y ~ i n ~ L i t e r s, ~ o t h e r s ~ i n ~ k i l o g r a m s . ~}$

eAccording to Jungbauer et al. (11).

controls, 23 subjects reported having at least one of the skin conditions depicted in the photo-questionnaire (15.2\%), and 14 of these reported severe skin conditions ( $9.3 \%$ of all controls). Symptoms on the fingers [including fingertips $(117,65.4 \%)]$ were most often reported by cases, followed by the arms $(98,54.7 \%)$, the face $(87$, $48.6 \%)$, and the hands $(75,41.9 \%)$. In the control group, 8 subjects (5.3\%) reported eczematous skin conditions on the fingertips/fingers/hands. Six of them reported severe skin conditions.

\section{Determinants of epoxy allergy}

The results of the univariate and multiple logistic regression analyses are shown in Table 3. After adjustment, positive and statistically significant associations were found between epoxy allergy and intensity of exposure to epoxy products (hours per week; unusually high exposure to epoxy products), wearing short sleeves or short trousers, and not always using the right type of gloves. Working years with epoxy products and not using skin cream were inversely associated with epoxy allergy. Figure 1 shows smoothed plots representing the relationship between epoxy allergy and years of working experience and number of hours per week spent working with epoxy products. Years of working experience showed a steep inverse association with epoxy allergy until 20 years, after which the magnitude of the association levelled off. Working hours per week showed a $\log$-linear association with epoxy allergy. Upon exclusion of controls with any self-reported skin symptoms (not necessarily epoxy allergy), no major differences in ORs were found. Similar, but less precise, risk estimates were obtained when only cases who reported severe symptoms were used (data not shown).

\section{Discussion}

The objective of our case-control study was to establish determinants associated with epoxy allergy in construction workers. We found strong associations of work hygiene behaviour and personal protection at the workplace with epoxy allergy. Wearing suitable gloves, long sleeves, and long trousers, even when it is warm, seems to protect against epoxy allergy, as does carefully working to avoid accidents such as a snapping injection hose and a vigorous exothermic reaction when resin and hardener are mixed.

The association with accidental exposure agrees with the findings of Kanerva et al. (18), who showed that a single accidental exposure to epoxy compounds may cause skin sensitization. Use of any type of glove, whether chemically resistant or not, showed no association, indicating that gloves made of cotton, leather and latex (household 
Table 3. Determinants of epoxy allergy analysed in 179 cases and 151 controls

\begin{tabular}{|c|c|c|c|c|c|c|}
\hline Variable & $\mathrm{n}$ cases & $\mathrm{n}$ controls & Crude OR & $95 \% \mathrm{Cl}$ & Adjusted OR ${ }^{a}$ & $95 \% \mathrm{Cl}$ \\
\hline Age (per 10-year increase) & 136 & 150 & $1.05^{\mathrm{b}}$ & $0.86-1.29$ & 1.26 & $0.95-1.66$ \\
\hline \multicolumn{7}{|l|}{ Have you ever suffered from hay fever? } \\
\hline No & 126 & 107 & Reference & - & - & - \\
\hline Yes/don't know & 32 & 24 & 1.21 & $0.66-2.21$ & - & - \\
\hline \multicolumn{7}{|l|}{ Do you use a skin cream? } \\
\hline Yes, more than once a day & 49 & 26 & Reference & - & Reference & - \\
\hline Yes, daily & 84 & 56 & 0.80 & $0.44-1.43$ & 0.60 & $0.28-1.25$ \\
\hline Yes, less than daily & 15 & 25 & 0.32 & $0.14-0.71$ & 0.32 & $0.12-0.86$ \\
\hline No & 20 & 32 & 0.33 & $0.16-0.69$ & 0.22 & $0.08-0.59$ \\
\hline Years of working with epoxy (per 10-year increase) & 151 & 138 & 0.52 & $0.39-0.69$ & 0.41 & $0.27-0.61$ \\
\hline Number of working hours a week (per 10-h increase) & 146 & 117 & 1.89 & $1.56-2.29$ & 1.72 & $1.39-2.14$ \\
\hline \multicolumn{7}{|l|}{$\begin{array}{l}\text { Have you ever had unusually high dermal exposure to epoxy } \\
\text { products? }\end{array}$} \\
\hline No & 82 & 98 & Reference & - & Reference & - \\
\hline Yes & 38 & 19 & 2.39 & $1.28-4.46$ & 2.13 & $1.01-4.51$ \\
\hline Don't know & 37 & 18 & 2.46 & $1.30-4.64$ & 1.50 & $0.70-3.20$ \\
\hline \multicolumn{7}{|l|}{ Do you use gloves when working with epoxy products? } \\
\hline Always & 132 & 119 & Reference & - & - & - \\
\hline Not always & 44 & 24 & 1.65 & $0.95-2.88$ & - & - \\
\hline \multicolumn{7}{|l|}{$\begin{array}{l}\text { What type of gloves most resembles the gloves you use when } \\
\text { working with epoxy product? }\end{array}$} \\
\hline Only chemically resistant gloves ${ }^{c}$ & 35 & 51 & Reference & - & Reference & - \\
\hline (Also) other types of gloves & 143 & 97 & 2.15 & $1.30-3.55$ & 2.12 & $1.12-4.01$ \\
\hline \multicolumn{7}{|l|}{ How often do you change gloves? } \\
\hline More than once a day & 55 & 39 & Reference & - & - & - \\
\hline Once a day & 35 & 46 & 0.54 & $0.30-0.98$ & - & - \\
\hline $\begin{array}{l}\text { Less than once a day or at irregular moments (e.g. just } \\
\text { when dirty/torn) }\end{array}$ & 79 & 57 & 0.98 & $0.58-1.68$ & - & - \\
\hline \multicolumn{7}{|l|}{ Are your gloves comfortable enough? } \\
\hline Yes & 140 & 128 & Reference & - & - & - \\
\hline No & 28 & 14 & 1.83 & $0.92-3.63$ & - & - \\
\hline \multicolumn{7}{|l|}{ Do you change clothes after working with epoxy products? } \\
\hline Yes, at work & 72 & 59 & Reference & - & - & - \\
\hline At home/not at all & 103 & 88 & 0.96 & $0.61-1.50$ & - & - \\
\hline \multicolumn{7}{|l|}{ Do you shower after working with epoxy products? } \\
\hline Yes, at work & 15 & 5 & Reference & - & - & - \\
\hline At home/not at all & 160 & 136 & 0.39 & $0.14-1.11$ & - & - \\
\hline \multicolumn{7}{|l|}{$\begin{array}{l}\text { Do you wash your hands directly after working with epoxy } \\
\text { products? }\end{array}$} \\
\hline Always & 77 & 70 & Reference & - & - & - \\
\hline Most times & 65 & 41 & 1.44 & $0.87-2.39$ & - & - \\
\hline Sometimes/never & 31 & 26 & 1.08 & $0.59-2.00$ & - & - \\
\hline \multicolumn{7}{|l|}{ Do you wash your hands before eating? } \\
\hline Always & 137 & 109 & Reference & - & - & - \\
\hline Most times/sometimes/never & 38 & 32 & 0.94 & $0.55-1.61$ & - & - \\
\hline \multicolumn{7}{|l|}{ How often do you wash your hands during a working day? } \\
\hline At least five times a day & 110 & 77 & Reference & - & - & - \\
\hline Less than five times a day & 60 & 62 & 0.68 & $0.43-1.07$ & - & - \\
\hline \multicolumn{7}{|l|}{ How do you clean your hands? } \\
\hline With a special handcleaner & 73 & 66 & Reference & - & - & - \\
\hline $\begin{array}{l}\text { Only with water, water and soap, water and abrasive } \\
\text { soap, or a solvent }\end{array}$ & 101 & 75 & 1.22 & $0.78-1.90$ & - & - \\
\hline \multicolumn{7}{|l|}{$\begin{array}{l}\text { During summer, do you wear clothes with short sleeves or } \\
\text { short trousers when working with epoxy products? }\end{array}$} \\
\hline No & 50 & 43 & Reference & - & Reference & - \\
\hline Sometimes & 58 & 58 & 0.86 & $0.50-1.49$ & 0.95 & $0.48-1.89$ \\
\hline Yes, always when it is warm & 60 & 26 & 1.98 & $1.07-3.67$ & 2.38 & $1.03-5.52$ \\
\hline \multicolumn{7}{|l|}{$\begin{array}{l}\text { Do you wear cuffs or gloves with cuffs when working with } \\
\text { epoxy products? }\end{array}$} \\
\hline Always & 46 & 35 & Reference & - & - & - \\
\hline Sometimes & 44 & 42 & 0.80 & $0.43-1.47$ & _- & _ \\
\hline Never & 58 & 59 & 0.75 & $0.42-1.32$ & - & - \\
\hline
\end{tabular}


Table 3. Continued

\begin{tabular}{|c|c|c|c|c|c|c|}
\hline Variable & $\mathrm{n}$ cases & n controls & Crude OR & $95 \% \mathrm{Cl}$ & Adjusted OR ${ }^{a}$ & $95 \% \mathrm{Cl}$ \\
\hline \multicolumn{7}{|c|}{ Do you wear boots or gaiters when working with epoxy products? } \\
\hline Always & 18 & 13 & Reference & - & - & - \\
\hline Sometimes & 23 & 24 & 0.69 & $0.28-1.73$ & - & - \\
\hline Never & 116 & 86 & 0.97 & $0.45-2.10$ & - & - \\
\hline \multicolumn{7}{|l|}{$\begin{array}{l}\text { Do you wear knee protection when working on your knees } \\
\text { with epoxy products? }\end{array}$} \\
\hline Yes, always & 90 & 62 & Reference & - & - & - \\
\hline Yes, most times/sometimes/never & 19 & 17 & 0.56 & $0.33-0.95$ & - & - \\
\hline $\begin{array}{l}\text { Not applicable, as I never worked on my knees with } \\
\text { epoxy products }\end{array}$ & 35 & 16 & 1.51 & $0.77-2.96$ & - & - \\
\hline \multicolumn{7}{|l|}{$\begin{array}{l}\text { How do you combine the epoxy resin and hardener of the } \\
\text { epoxy product that you work most with? }\end{array}$} \\
\hline $\begin{array}{l}\text { Resin and hardener were in a dosage system/resin and } \\
\text { hardener were in a closed system/the hardener was } \\
\text { poured into the resin }\end{array}$ & 49 & 54 & Reference & - & - & - \\
\hline \multicolumn{6}{|l|}{ How do you mix the epoxy product that you work most with? } & - \\
\hline $\begin{array}{l}\text { Using an electric mixer in an open barrel/using a closed } \\
\text { system/using a package that allows kneading without } \\
\text { opening }\end{array}$ & 138 & 113 & Reference & - & - & - \\
\hline Manually in an open barrel & 31 & 27 & 0.94 & $0.53-1.67$ & - & - \\
\hline \multicolumn{7}{|l|}{$\begin{array}{l}\text { How do you clean the tools of the epoxy product you work } \\
\text { most with? }\end{array}$} \\
\hline No cleaning, as tools were disposed of & 26 & 28 & Reference & - & - & - \\
\hline $\begin{array}{l}\text { Dry cleaning with a wipe/with a solvent/by sanding the } \\
\text { tools/by other means }\end{array}$ & 142 & 115 & 1.33 & $0.74-2.39$ & - & - \\
\hline
\end{tabular}

CI, confidence interval; OR, odds ratio.

Owing to missing answers, not all categories add up to 330 subjects. Complete datasets $(n=25)$ were generated by multiple imputation. ORs were estimated by combining the results of logistic regression analysis of each multiply imputed dataset.

${ }^{a}$ Adjusted ORs were adjusted for age, years of working experience, number of working hours per week, ever having had an unusually high exposure to epoxy product during work, wearing no gloves other than chemically resistant gloves, wearing short sleeves, and using skin cream. ${ }^{b}$ Bold type indicates statistically significant associations $(p<0.05)$.

${ }^{\mathrm{c}}$ Nitrile and butyl rubber gloves, either entirely dipped or dipped to the cuff, are considered resistant to epoxies.

quality) do not adequately protect from skin exposure. In fact, in separate analyses, leather gloves, cotton gloves and latex household gloves were positively associated with epoxy allergy (data not shown), which confirms the conclusion of van Putten et al. (3) that inadequate gloves have an adverse effect on skin protection. The association with skin cream may be a matter of reverse causation, in the sense that people start using a skin cream once they observe their skin problems. The inverse association with years of working experience may point to a healthy worker survivor effect. Frequency of changing gloves and wearing knee protection were also inversely associated, but the associations were attenuated after adjustment. Only two earlier studies investigated determinants of epoxy exposure (6) and epoxy allergy $(1,7)$, in a small number of subjects. Fillenham etal. (6) reported the results of an observational study in 21 Swedish workers from eight companies, and found uncured epoxy resin on gloves, tools, and work areas. They also observed that the gloves used were often inadequate for handling epoxies. In a cross-sectional study in 22 workers from one company in Taipei, Chu et al. (7) showed that the development of allergy depends on various determinants, such as work hygiene. Workers who washed their hands after using epoxy products seemed to have a lower likelihood of developing epoxy allergy than those who did not wash their hands. In our study, the differences in hand hygiene were small: $43 \%(n=77)$ of the cases and $46 \%(n=70)$ of the controls always washed their hands directly after working with epoxy products. The association between poor hand hygiene and epoxy allergy was positive, but not significant.

As some controls were recruited at instruction sessions, we were unable to assess the effect of instruction in our study. However, in the group recruited directly at companies, we found a strong negative association with both oral and written safety and hygiene instruction (results not shown). Apart from the simple fact that measures tend to be more successful when people know why and how to apply them, this observation may emphasize the importance of instruction on safe working with epoxies.

The controls had worked for more years with epoxies, but the cases were exposed for more hours per week, and the cumulative exposure time of the cases was over twice 

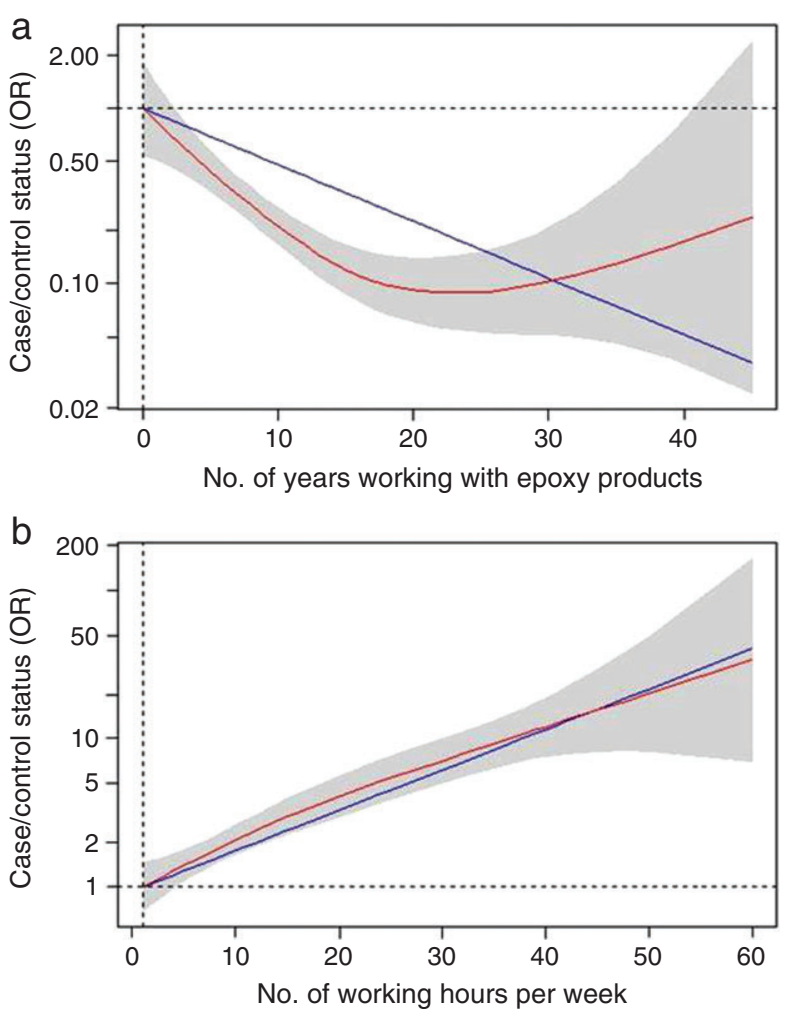

Fig. 1. Smoothed plots representing association between working years (a), hours per week working with epoxy products (b) and epoxy allergy, corrected for age. Red lines are based on a generalized additive model; blue lines illustrate presumed linearity, as used in the regression analyses. OR, odds ratio.

of that of the controls: cases, $150 \mathrm{~h} \times$ year/week; controls, $60 \mathrm{~h} \times$ year/week. The case group also used more products per week. Thus, epoxy allergy is associated with exposure duration per week, but negatively associated with years of exposure. The strong association between epoxy allergy and unusually high exposure also points to the importance of exposure intensity.

One of every five epoxy workers develops an allergy against epoxies $(3,4)$, and skin symptoms among the cases after epoxy exposure are severe. An important advantage of our study is that the cases were very well defined. All cases were shown to have epoxy allergy by means of a patch test. As expected, the prevalence of hand dermatitis among the cases was high: $88.8 \%$ had possible hand dermatitis and $55.9 \%$ had hand dermatitis according to the symptom-based questionnaire. On the photo-questionnaire, $69.3 \%$ of the cases reported skin symptoms in the highest of three categories of severity. According to the symptom-based questionnaire, $9.2 \%$ of the controls had possible hand dermatitis, and 2.2\% had hand dermatitis. The prevalence of dermatitis among the controls was remarkably low. Timmerman et al. (10) mentioned a self-reported prevalence of contact dermatitis of $46.9 \%$ among construction workers. Glove use to prevent epoxy allergy may also help to prevent other skin symptoms. Furthermore, once an epoxy allergy has developed, people tend to leave the job, which may also mask the presence of other skin symptoms. Bansgaard et al. (19) studied the fate of workers who developed epoxy allergy and found that $>80 \%$ of them avoided further exposure (change of workplace/tasks; end of job; sick leave). On the other hand, Mascaro et al. found that, in the general working population in Spain, $18 \%$ of persons with severe hand dermatitis reach a state of permanent disability (20). The questions in the Dutch study (10) were slightly different from those in our study, which makes comparison of the results somewhat uncertain. Owing to the low prevalence of dermatitis in the control group, we decided not to test the controls for epoxy allergy. In the study by Chu et al. (7), none of the asymptomatic workers reacted to the epoxy components in the patch test. Our results did not change when symptomatic controls were excluded, so we believe it unlikely that undiagnosed controls influenced the current findings. The time lag between first exposure and the development of symptoms is remarkably long. Bansgaard et al. (19) found that, among epoxy workers, $62.4 \%$ develop a skin allergy within 1 year. The explanation for this is that the occupational insurance starts after the vocational training and the probationary period. People who develop an allergy within this time are not registered in the files of BGBAU. As a consequence, the people who are most susceptible to sensitization are missed, and the number of sensitized people is underestimated.

Potential risk factors were assessed by use of a self-completed questionnaire. Retrospective data collection by questionnaire has potential limitations, such as recall bias, misclassification in answers, and socially desirable answers. To be sure that the questions were clear to the target group, we mainly used questions from validated questionnaires $(8,9)$. New questions were validated in a field study, which is reported elsewhere (10). The response for the control group was relatively low (29\%) as compared with the case group (50\%). We cannot exclude some degree of selection bias resulting from overrepresentation of controls with safer working practices, although companies were not specifically selected for good working practices. Therefore, we believe that selection bias is not a major problem in this study. Also, cases and controls showed a similar age distribution, and had work experience in the same industry. However, some overestimation of the effect of control measures cannot be entirely excluded. A longitudinal, prospective 
study would overcome this limitation, as subjects are included before disease onset. As compared with other questionnaire studies in the construction industry, $29 \%$ is not a poor response. Hoonakker et al. reported responses varying from $8 \%$ to $27 \%$ for questionnaire studies in the construction industry (21). In conclusion, skin symptoms associated with epoxy allergy are severe. Poor occupational hygiene behaviour and poor personal protection are strong determinants for epoxy allergy. In particular, avoiding accidents, wearing chemically resistant gloves and avoiding having bare arms and legs appear to prevent or delay the development of epoxy allergy.

\section{Acknowledgements}

The authors thank Katrin Schäfer for many telephone calls to subjects, and Yvonne Schäfer for organizing the sessions on epoxies. The permission of Dr Harma Stenveld from the Dutch Centre for Occupational Skin Diseases to use the photo-questionnaire is gratefully acknowledged.

\section{References}

1 Anveden Berglind I, Lind M L, Lidén C. Epoxy pipe relining - an emerging contact allergy risk for workers. Contact Dermatitis 2012: 67: 59-65.

2 Geier J, Krautheim A, Uter W et al. Occupational contact allergy in the building trade in Germany: influence of preventive measures and changing exposure. Int Arch Occup Environ Health 2011: 84: 403-411.

3 van Putten P B, Coenraads P J, Nater J P. Hand dermatoses and allergic reactions in construction workers exposed to epoxy resins. Contact Dermatitis 1984: 10: 146-150.

4 Rømyhr O, Nyfors A, Leira H L, Smebold H T. Allergic contact dermatitis caused by epoxy resin. Contact Dermatitis 2006: 55 : 167-172.

5 Rühl R, Wriedt H. Some economic benefits of REACH. Ann Occup Hyg 2006: 50 : 541-544.

6 Fillenham G, Lidén C, Anveden Berglind I. Skin exposure to epoxy in the pipe relining trade - an observational study. Contact Dermatitis 2012: 67: 66-72.

7 Chu C U, Pontén A, Sun C C, Jee S H. Concomitant allergy to resins, reactive diluents and hardener of a bisphenol A/F based epoxy resin in subway construction workers. Contact Dermatitis 2006: 54: 131-139.
8 Burney P G, Luczynska C, Chinn S, Jarvis D. The European community respiratory health survey. Eur Respir J 1994: 7: 954-960.

9 Smit H A, Coenraads P J, Lavrijsen A P et al. Evaluation of a self-administered questionnaire on hand dermatitis. Contact Dermatitis 1992: 26: 11-16.

10 Timmerman J G, Zilaout H, Heederik D et al. Validation of a questionnaire on hand hygiene in the construction industry. Ann Occup Hyg 2014: 58: 1046-1056.

11 Jungbauer F H, Piebenga W P, ten Berge E E et al. NVAB richtlijn: Preventie Contacteczeem [NVAB Guideline: Prevention of Contact Dermatitis]: Utrecht, Nederlandse Vereniging voor Arbeids- en Bedrijfsgeneeskunde, 2006 (ISBN 13:978-90-76721-11-8).

$12 \mathrm{http} / / /$ www.huidenarbeid.nl/tests/ index.cfm?action $=$ display\&test_id $=14$ (last accessed 4 January 2016)

13 van der Walle H B, Piebenga W P. Skin and Occupation: Arnhem, Centre for Skin and Occupation, 2004.

14 van Buuren S. Multiple imputation of discrete and continuous data by fully conditional specification. Stat Methods Med Res 2007: 16: 219-242.

15 Eide G E, Gefeller O. Sequential and average attributable fractions as aids in the selection of preventive strategies. J Clin Epidemiol 1995: 48: 645-655.

16 Rückinger S, von Kries R, Toschke AM. An illustration of and programs estimating attributable fractions in large scale surveys considering multiple risk factors. BMC Med Res Methodol 2009: 9: 7.

17 https://www.federa.org/sites/default/ files/bijlagen/coreon/code_of_conduct_ for_medical_research_1.pdf (last accessed 4 January 2016).

18 Kanerva L, Tarvainen K, Pinola A et al. A single accidental exposure may result in a chemical burn, primary sensitization and allergic contact dermatitis. Contact Dermatitis 1994: 31: 229-235.

19 Bansgaard N, Thyssen J P, Menné T et al. Contact allergy to epoxy resin: risk occupations and consequences. Contact Dermatitis 2012: 67: 73-77.

20 Mascaro J M, Querol I, Lindner L et al. Costs of patients with occupational severe chronic hand eczema refractory to topical corticosteroids for employer's mutual insurance companies in Spain. Value Health 2009: 12: A453-A454.

21 Hoonakker P, Carayon P, Loushine T. Barriers and benefits of quality management in the construction industry: an empirical study. Total Qual Manage 2010: 21: 953-969. 